\title{
Climatic Maps for Passive Cooling Methods Utilization in Thailand
}

\author{
Athasit Jittawikul*1, Ikuo Saito ${ }^{2}$ and Osamu Ishihara ${ }^{3}$ \\ ${ }^{1}$ Researcher, Graduate School of Science and Technology, Kumamoto University, Japan \\ ${ }^{2}$ Professor, Department of Civil Engineering and Architecture, Yatsushiro National College of Technology, Japan \\ ${ }^{3}$ Professor, Faculty of Engineering, Kumamoto University, Japan
}

\begin{abstract}
The aim of the present study is to decrease environmental impacts, particularly of cooling in tropical areas such as Thailand by utilizing passive cooling methods. To utilize passive cooling methods effectively, it is important to understand the climatic characteristics of each region through out the year. The current paper introduces the methodology of meteorological data arrangement and visualization of climatic characteristics in composing the climatic maps. The investigation showed the details of climatic distributions would be useful for the thermal environment design. Moreover, consideration of natural energy utilization in passive cooling design would be the logical next step.
\end{abstract}

Keywords: passive cooling method; meteorological data arrangement; climatic map

\section{Introduction}

In developing countries, environmental impacts such as carbon dioxide are not easy to diminish. These countries do not adequately address ecological activities. Economic development is a priority, and it is difficult to solve environment problems and expand the economy simultaneously.

Figure 1 tracks change in electricity consumption by economic sector from 1990 to 2001 in Thailand showing an increase from year to year. The residential sector is increasing gradually, depending on changes in the economic conditions of the other sectors. In the near future, energy consumption demand in the residential sector will increase continuously, with a corresponding increase in exhaust emissions. Figure 2 shows the location and climatic zones of Thailand and neighboring countries. Figure 3 presents the climatic characteristics of several cities that differ remarkably in temperature and humidity.

As might be expected, steps to reduce exhaust emissions for residential use maybe necessary, so as not to interrupt economic activities. The most possible method is to implement measures for residential energy savings. In hot humid areas such as Thailand, passive cooling is one method of energy conservation that could also reduce the environmental load.

However an understanding of basic climatic conditions and regional characteristic is necessary. The objective

*Contact Author: Athasit Jittawikul, Kumamoto University, 239-1 Kurokami Kumamoto City, Kumamoto Prefecture 860-0862, Japan

Tel: +81-96-342-3559 Fax: +81-96-342-3569

e-mail: 012d9611@gsst.stud.kumamoto-u.ac.jp (athasitjp@hotmail.com)

(Received December 5, 2003; accepted April 6, 2004)

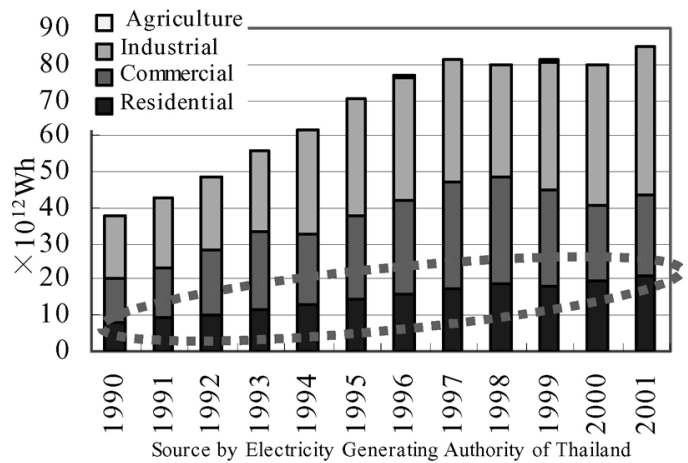

Fig.1. Electric consumption by sectors in Thailand

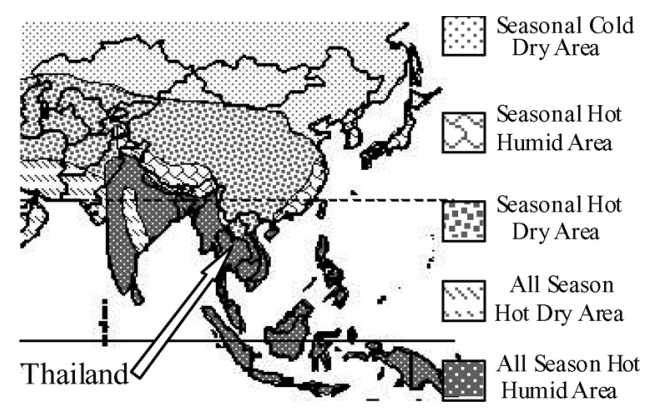

Fig.2. Climatic zone ${ }^{1)}$ and location of Thailand

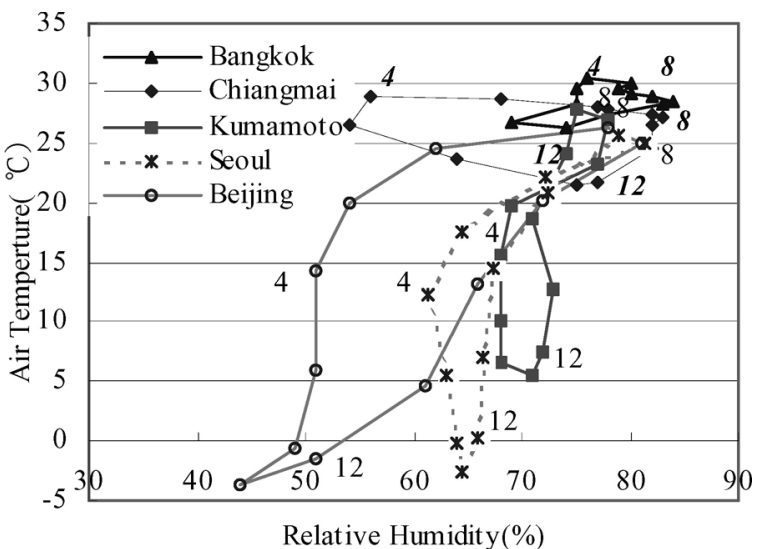

Fig.3. Climograph of principal cities in Thailand and Asia ${ }^{2)}$ 


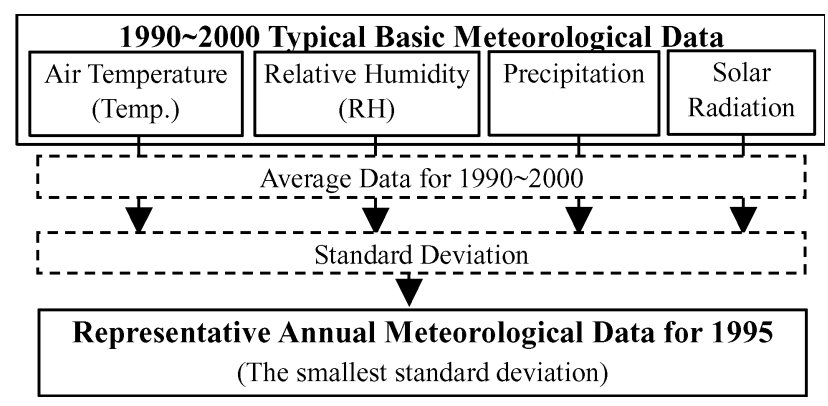

Fig.4. Selection of the representative year from standard deviation

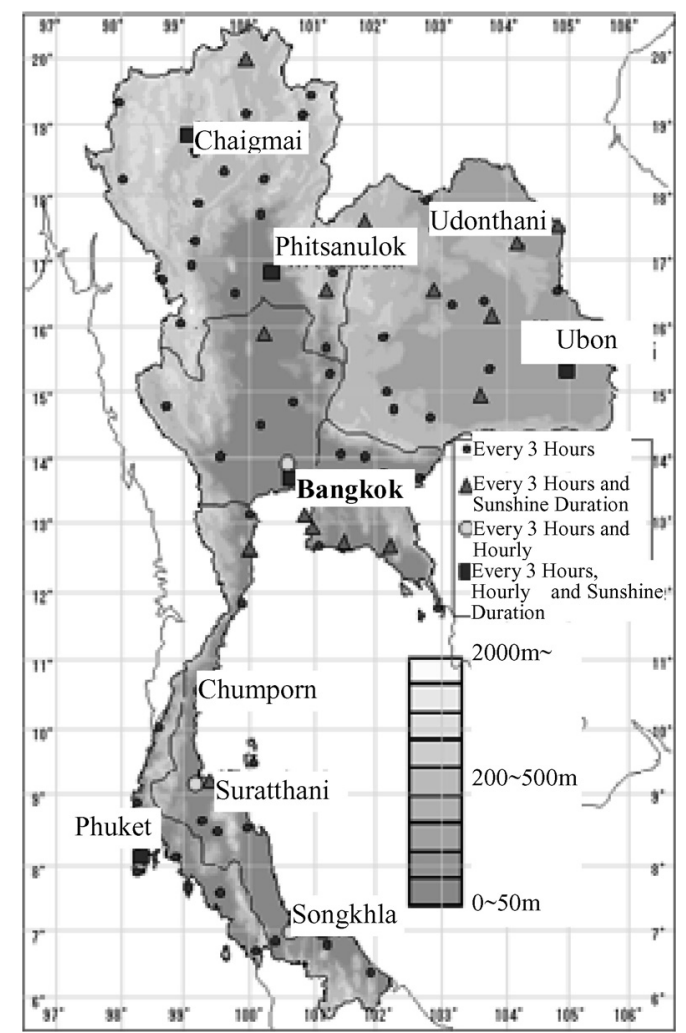

Fig.5. Observation points and altitude map of Thailand

of the current paper is to understand the characteristics of climatic and geographical variation using applied meteorological data to map the climatic maps.

\section{Methods}

\subsection{Preparation of Meteorological Data}

First, representative data for one-year were selected, calculated by standard deviation to be closest to the mean basic meteorological data of the most recent ten years (1991-2000) as shown in Figure 4. To draw climatic maps for environmental building design using meteorological data, the observatory candid data (Figure 4) obtained from the Thai Meteorological Agency must be arranged next. The year of 1995 was selected. Eighty-five every three-hours observatory points of temperature, relative humidity, cloud cover, wind direct, wind speed, 21 hourly observatory points of sunshine duration and 1 hourly observatory point of solar radiation have been prepared

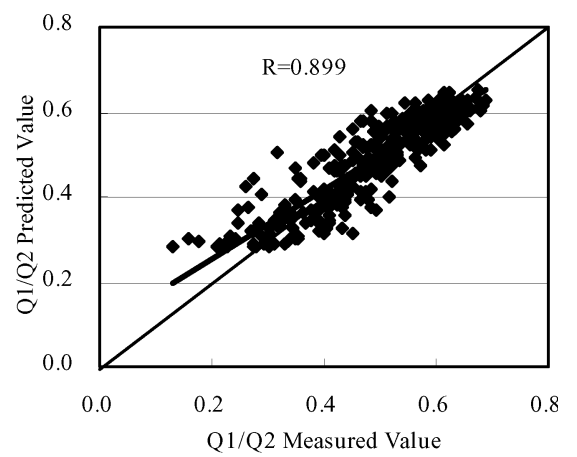

Fig.6. Correlation of solar radiation estimated in 2000

According to regression analysis, observed solar radiation data for year 2000 data for Bangkok were used to estimate the solar equation ${ }^{3), 4), 7)}$ as follows:

$\mathrm{Q} 1 / \mathrm{Q} 2=0.3445+0.4185 * \mathrm{~S} 1 / \mathrm{S} 2-0.0625 * \mathrm{SinH}$

Q1 : Daily Integrating Global Solar Radiation (observed data for 2000 in Bangkok) [kJ/m² day]

Q2 : Daily Integrating Extraterrestrial Solar Radiation $\left[\mathrm{kJ} / \mathrm{m}^{2} \mathrm{day}\right]$

S1 : Daily Integrating Sunshine Duration [hr]

S2 : Daily Integrating Possible Sunshine Duration [hr]

$\mathrm{H}$ : Solar Altitude [ $\left.{ }^{\circ}\right]$

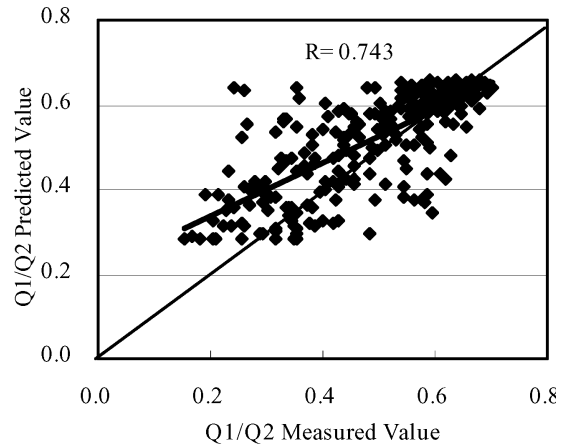

Fig.7. Correlation of solar radiation estimated in 1995 (using 2000 year estimated equation(1))

as standard weather data for climatic mapping.

Every three hours data were used as the basic meteorological data for 1995, except for the sunshine duration and solar radiation, which used hourly data, arranged by monthly mean value.

For the graphical data, an altitude map of Thailand obtained from the Thai Military Survey Agency was used to prepare the latitude, longitude and altitude of the observation points.

\subsection{Climatic Map Data Arrangement}

Solar radiation is estimated only at one observation point, in Bangkok. To estimate the solar radiation of an arbitrary point, 21 points of sunshine duration data were utilized $^{3)}$. To estimate solar radiation ${ }^{3), 4), 7)}$ from the high correlation between the measured value and the predicted value of the solar radiation ratio shown above in Figure6, losing data of the year 1995, the estimate equation for 
the year 2000 was used to estimate the horizontal solar radiation in 1995 .

From this estimate equation (1), solar radiation was estimated by substituting 1995 sunshine duration data. Figure 7 shows the correlation between measured and predicted values using the year 2000 estimate equation.

According to a previous related field investigation ${ }^{8)}$ for temperature and humidity data, the correction of these data for latitude and altitude is more effective. In present study also confirms the interaction between climatic data and geographical data, based on air temperature and absolute humidity. There is a strong correlation between latitude and altitude and air temperature and absolute humidity through out the year at all observatory points.

The examined results confirmed that temperature and humidity were affected by latitude and altitude. The regression analysis resulted in the typical month data that were shown in estimate equations (2) to (7), which could compute the reduction ratio of air temperature and absolute humidity.

Equations (2) to (4) calculated the correction value of temperature to allow for latitude and altitude as shown below:

$$
\begin{aligned}
& \theta(\mathrm{AP})=26.453+0.32 * \mathrm{~L}-0.0084 * \mathrm{~A} \\
& \theta(\mathrm{AU})=26.475+0.118^{*} \mathrm{~L}-0.007 * \mathrm{~A} \\
& \theta(\mathrm{DE})=28.579-0.262 * \mathrm{~L}-0.0135 * \mathrm{~A}
\end{aligned}
$$

Using the same method as above, Equations (5) to (7) calculate the correction value of absolute humidity to allow for latitude and altitude as shown below:

$$
\begin{aligned}
& \chi(\mathrm{AP})=0.0204-0.0000965^{*} \mathrm{~L}-0.0000128^{*} \mathrm{~A} \\
& \chi(\mathrm{AU})=0.0182+0.0001046^{*} \mathrm{~L}-0.0000538^{*} \mathrm{~A} \\
& \chi(\mathrm{DE})=0.0216-0.0006219^{*} \mathrm{~L}+0.00000059 * \mathrm{~A} \\
& \theta(\mathrm{AP}): \text { Estimated air temperature in April }\left[{ }^{\circ} \mathrm{C}\right] \\
& \theta(\mathrm{AU}): \text { Estimated air temperature in August }\left[{ }^{\circ} \mathrm{C}\right] \\
& \theta(\mathrm{DE}): \text { Estimated air temperature in December }\left[{ }^{\circ} \mathrm{C}\right] \\
& \chi(\mathrm{AP}): \text { Estimated absolute humidity in April }[\mathrm{kg} / \mathrm{kg} \text { ' }] \\
& \chi(\mathrm{AU}): \text { Estimated absolute humidity in August }\left[\mathrm{kg} / \mathrm{kg}{ }^{\prime}\right] \\
& \chi(\mathrm{DE}): \text { Estimated absolute humidity in December }\left[\mathrm{kg} / \mathrm{kg}{ }^{\prime}\right] \\
& \mathrm{L} \quad: \text { Latitude }\left[{ }^{\circ}\right] \\
& \mathrm{A} \quad: \text { Altitude }[\mathrm{m}]
\end{aligned}
$$

\subsection{Climatic Mapping}

The process of drawing climatic maps is shown in Figure 8. After preparation of the meteorological data, the data were arranged to enable the climatic maps to be drawn effectively. After the necessary climatic data were arranged, the climatic maps were drawn by matching the locations of observatory points with sea levels from the altitude map.

In such loss data, altitude, latitude and distance correction were used to estimate arbitrary points, not including observed data. When the data were matched, climatic maps could be generated.

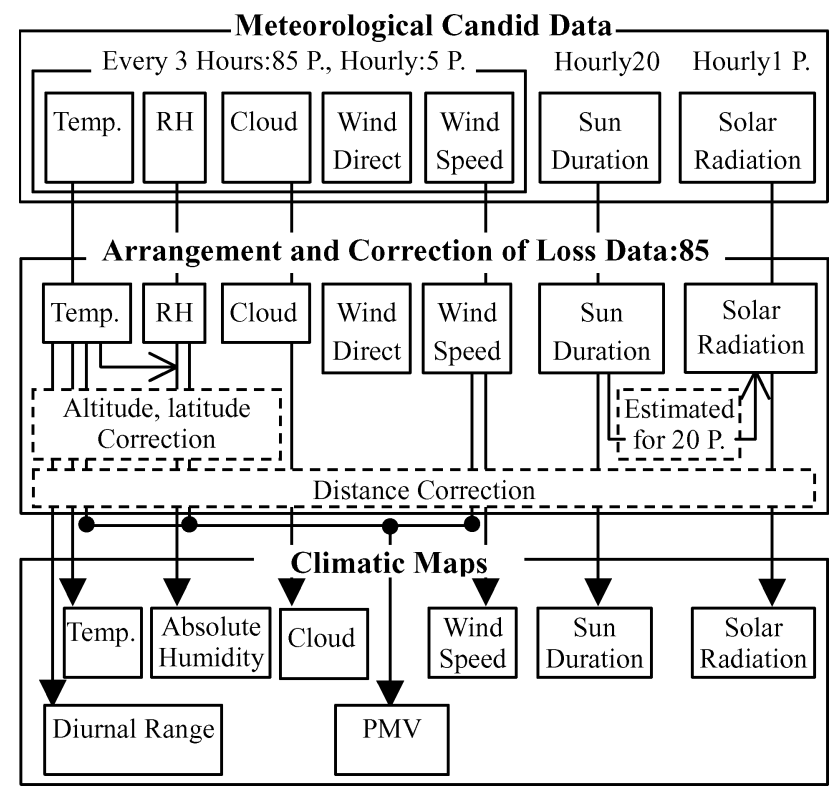

Fig.8. Flow of meteorological data arrangement and drawing of climatic maps

Distance correction is referring to previous current study $^{8)}$. The calculated equation is as follows:

$$
\left.\mathrm{W}^{\prime}=\underset{\mathrm{i}=1}{\mathrm{n}} \stackrel{\mathrm{W}}{\mathrm{n}} \mathrm{W}_{\mathrm{i}} / \mathrm{D}_{\mathrm{i}}^{2}\right) / \underset{\mathrm{i}=1}{\left(\sum 1 / \mathrm{D}_{\mathrm{i}}^{2}\right)}
$$

W' : Arbitrary meteorological data

$\mathrm{W}_{\mathrm{i}}$ : Observatory meteorological data

$\mathrm{D}_{\mathrm{i}}$ : Distance between arbitrary point and surrounding observation points

$\mathrm{n}$ : Number of observation points

\section{Results and Discussions}

The climatic maps indicated the year 1995 could be considered as typical of climatic features in Thailand. The analysis of climatic features reveals the typical seasons in Thailand. The hot-dry season (hot season) occurs in April, the hot-humid season (rainy season) in August, and the cool season in December.

Air Temperature (Figure 9)

In April, a very high temperature area spreads over most of the inland area, especially north of the central part of Thailand. A similar distribution of high temperature expansion appears in August. In December, the temperature is comparatively low. However, the geographic temperature distribution shows a dependence on altitude, as expected.

\section{Absolute Humidity (Figure 10)}

The humidity distribution shows a similar characteristic during April and August, decreasing with altitude. A high absolute humidity value expands to most of the central and northeastern part in August. However, in December humidity decreases more with latitude than with altitude. 


\section{Cloud Cover (Figure 11)}

During the hot-dry season, a relatively low degree of cloudiness occurs, changing with latitude. In contrast, there is no change of cloudiness during the rainy season in August. However, cloud cover is notably thicker in the western mountainous area.

\section{Sunshine Duration (Figure 12)}

On the whole, sunshine duration is longer in April and shorter in August. However, in December there is a remarkable difference between the inland area (where it is comparatively longer) and southern area (where it is shorter).

\section{Horizontal Solar Radiation (Figure 13)}

In April, there is a great deal of solar radiation across the whole country. The amount of solar radiation in August and December is not sufficient, when compared with the hot-dry season.

Wind Speed (Figure 14)

Throughout the year, there is no conspicuous change in wind speed in any part of the country. In December, the wind speed appears to be higher in the south-eastern part of northeastern Thailand. However, except in some parts of the southern, central and eastern parts, the utilization of wind speed as a conservation method e.g. draft ventilation could not be expected.

\section{Diurnal Range (Figure 15)}

A similarity exists between the diurnal ranges in April and December, which increase with latitude. During the dry season, especially in April in northern Thailand, the diurnal range has a high value. In August, however, it is difficult to apply this condition effectively for night chill. PMV 9), 10) (Figure 16)

Predicted mean vote (PMV) index is calculated through a complex mathematical function of human activity, clothing and environmental parameters. This study used 0.6 clo of clothing insulation and 1.2 of metabolic rate for the PMV calculation. The ambient input data are temperature, absolute humidity and wind speed as shown in Figure 8.

The basic equation ${ }^{11)}$ of PMV index developed by Fanger (1973) is shown below.

$$
\mathrm{PMV}=\{0.352 \exp (-0.042 \mathrm{QH} / \mathrm{Ab})+0.032\} \mathrm{Qs}
$$

$\mathrm{Q}_{\mathrm{H}}$ : Rate of body heat production [W]

$\mathrm{Ab}:$ Area of the body $\left[\mathrm{m}^{2}\right]$ (between $1.7 \sim 1.8 \mathrm{~m}^{2}$ )

Qs : Index of heat stress is given by radiation, convection, diffusion, evaporative and respiratory losses [W]

(PMV scale: -3 cold, -2 cool, -1 slightly cool, 0 neutral, 1 slightly warm, 2 warm, 3 hot)

A remarkable feature of PMV is appeared during hot season in April and August. Most of the central and northeastern parts of Thailand indicate a slightly warmer PMV index. The appearance of the PMV is extremely similar to the feature of the air temperature distribution.

\section{Conclusions}

Passive cooling methods could be suggested as effective energy-saving measures in hot humid areas such as in Thailand. However, passive methods are easily influenced by regional characteristics. The objective of the present study is to understand the characteristics of climatic and geographical variation using applied meteorological data to map the climatic maps. The paper can be summarized as follows:

1. The present paper describes the climatic characteristics across all regions of Thailand needed for thermal environmental design. The standard weather data arrangement was prepared by utilizing meteorological data and the characteristic climatic maps were drawn.

2. Although Thailand is located in the all season hothumid zone, it is clear in the present study, that the climatic maps show distinct hot dry, hot humid, and cool seasons in Thailand.

3. The maps of air temperature, absolute humidity and PMV, indicate a correlation with the latitude and altitude.

4. The climatic maps demonstrate that utilization of natural energy is affected by the different regional characteristics.

The efficiency of regional passive cooling method should be investigated, and further analysis of natural energy utilization potential maps should be completed.

\section{Acknowledgements}

The authors would like to acknowledge the Thai Meteorological Agency for providing the data, and also for the assistances of many peoples.

\section{References}

1) K. Kimura, The technology of natural energy in folk dwelling

2) National Astronomical Observatory, Chronological Scientific Tables 2000

3) S. Yoshida, S. Shinoki, Preparation of the Maps of monthly mean global solar radiation and its year to year variability for the Japanese Islands, TENKI, Vol.25, No.5, pp. 61-75, 1978

4) T. Watanabe, Y. Urano, et al., Procedures for Separating direct and Diffuse Insolation on A Horizontal Surface and Prediction of Insolation on Tilted Surfaces, J. Arc. Planning \& Environmental Eng., AIJ, No.330, pp.96-108, 1983.8

5) Information Service Division, Thai Meteorological Agency

6) Y. Urano, Passive Cooling of The House

7) I. Saito, O. Ishihara, A study on production of regional weather data for utilization of natural energy, Part1 estimation of solar radiation, Journal of REIMAN, No.18, pp.47-50, Nov., 1996

8) K. Nishikawa, I. Saito, O. Ishihara, et al. Preparation of meteorological data and climate maps for natural energy utilization, J. Arc. Planning \& Environmental Eng., AIJ, No.509, pp.15-20, Jul., 1998

9) ASHARE Transaction 1986

10) M. Santamouris et al., Passive Cooling of Buildings

11) N.K. Bansal et al., Passive Building Design 


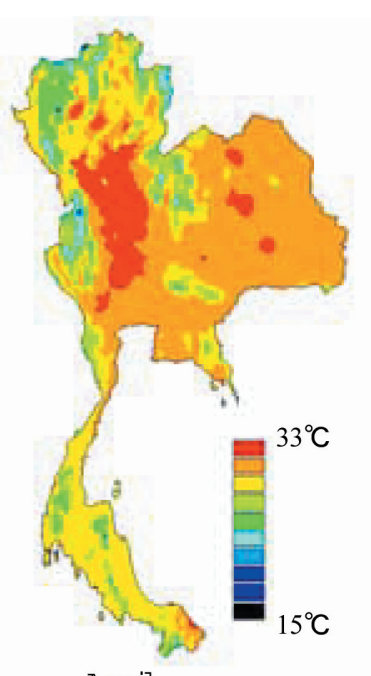

April

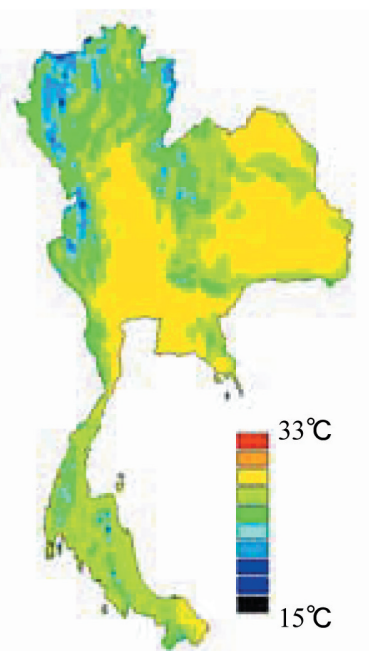

August

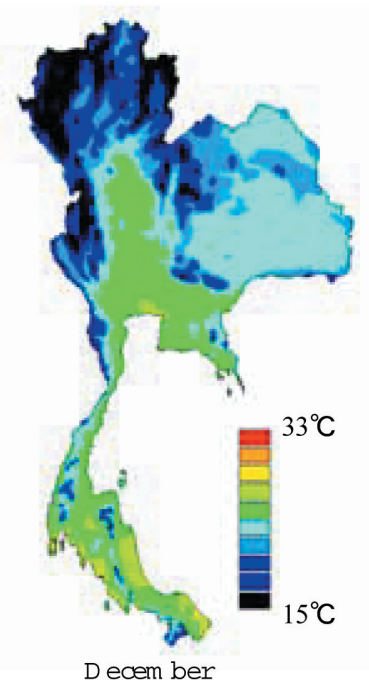

Fig.9. Maps of air temperature
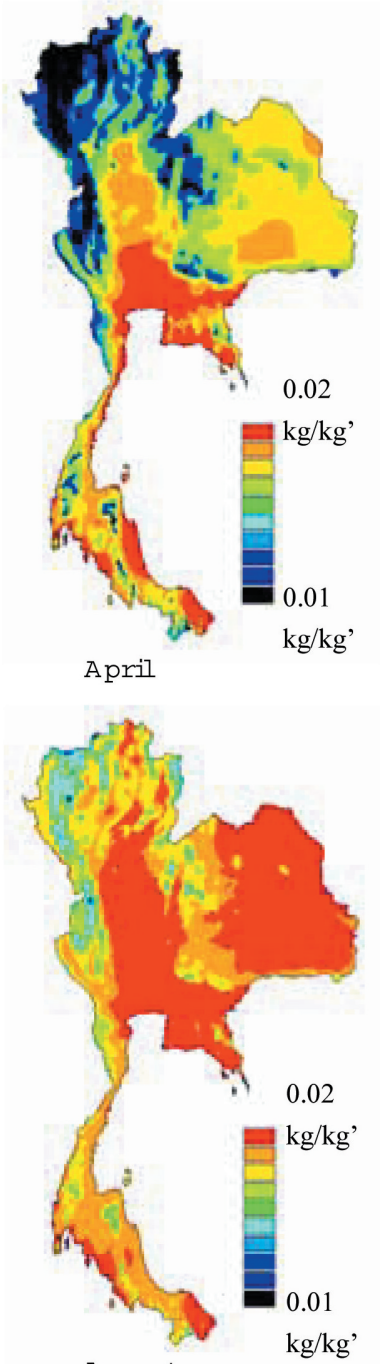

August

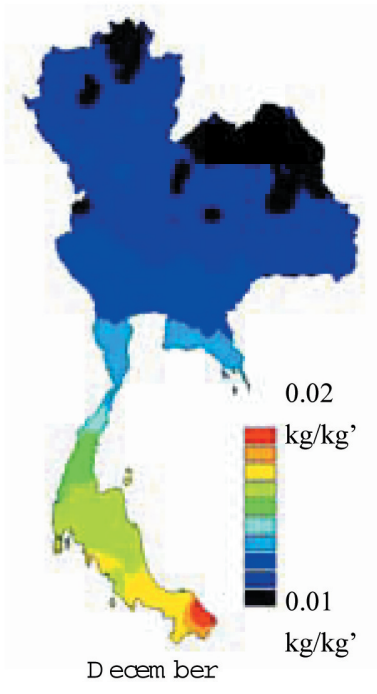

Fig.10. Maps of absolute humidity
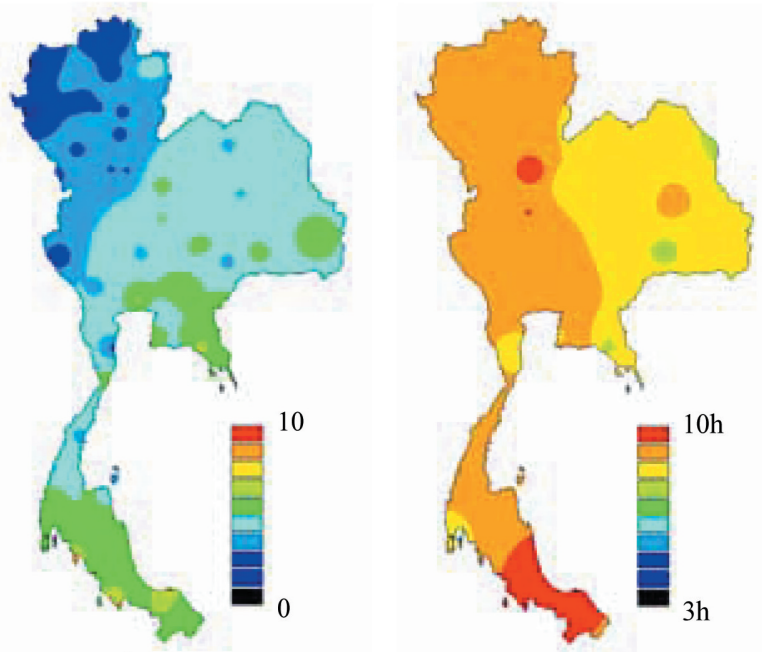

April

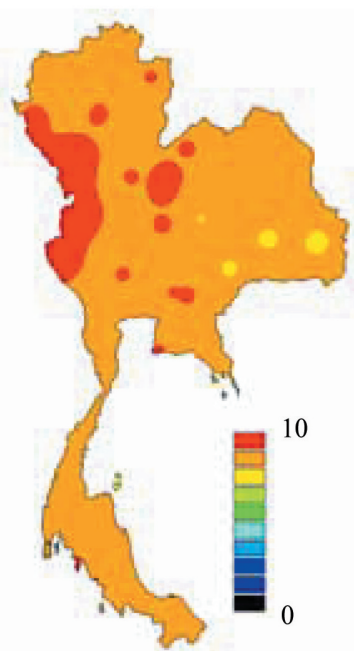

August

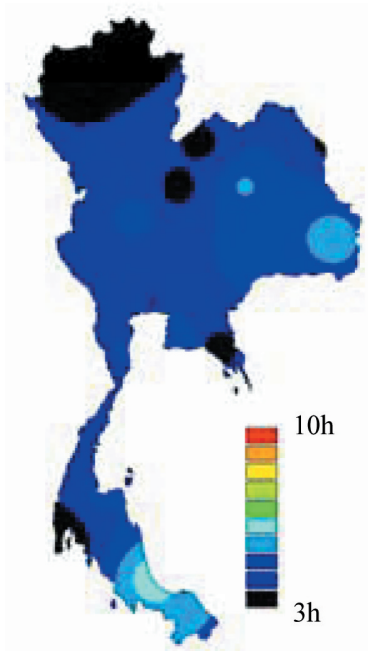

August

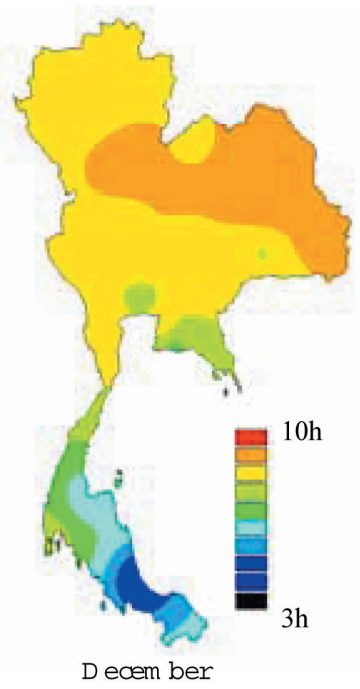

Fig.12. Maps of

sunshine duration 


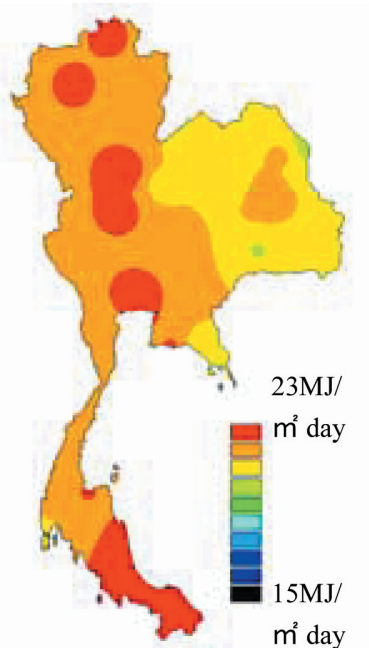

April

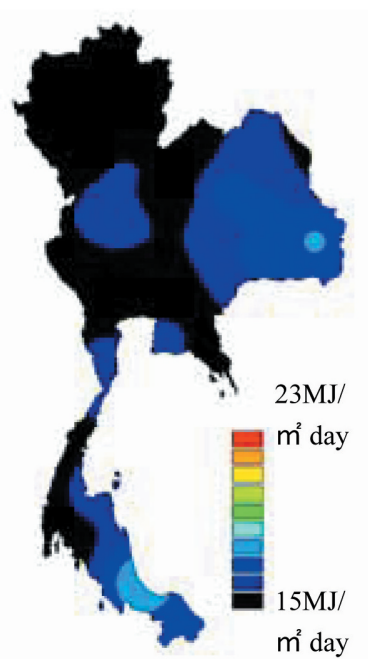

August

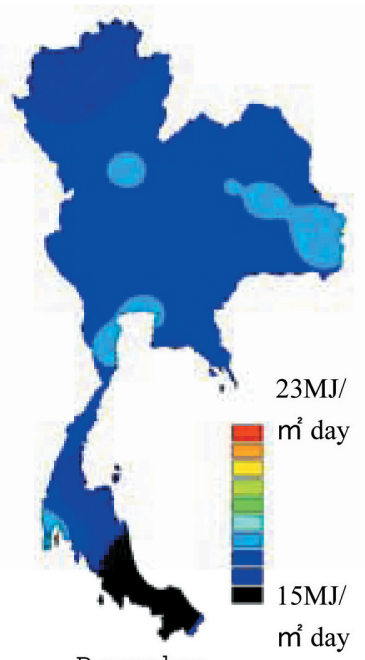

Fig.13. Maps of solar radiation

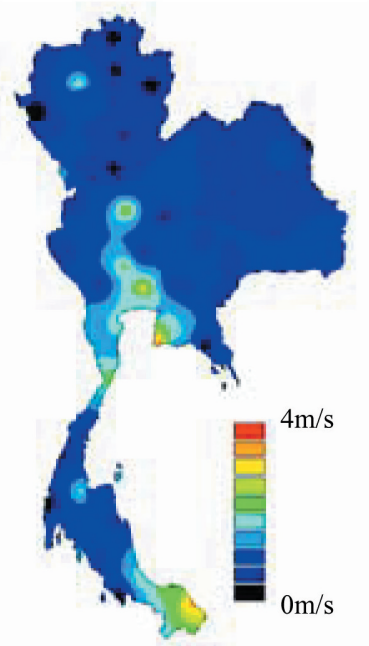

April

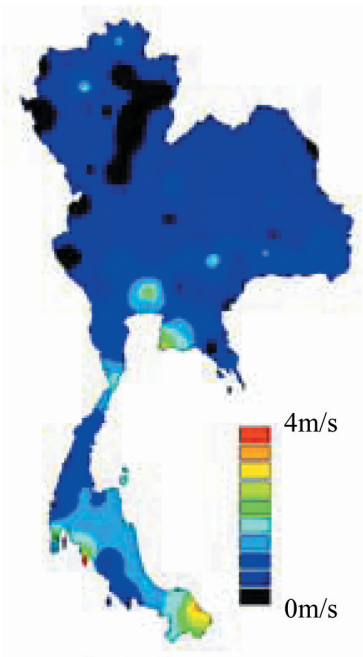

August

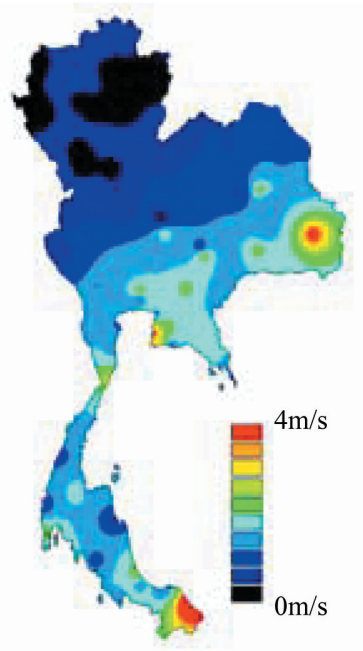

D ecem ber

Fig.14. Maps of wind speed
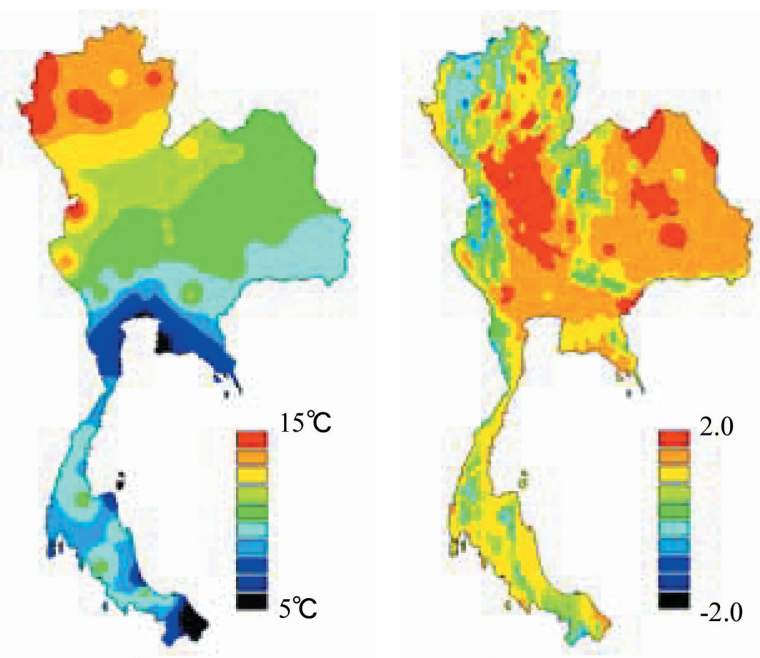

April

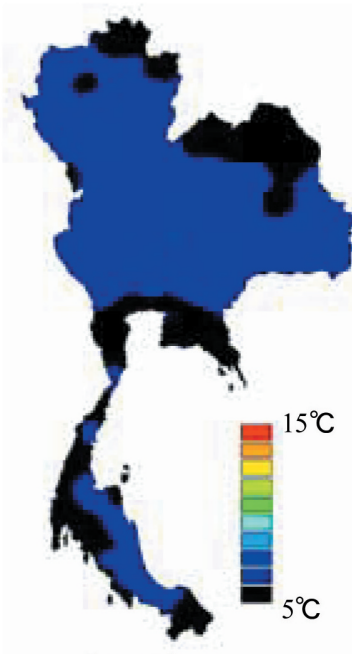

August

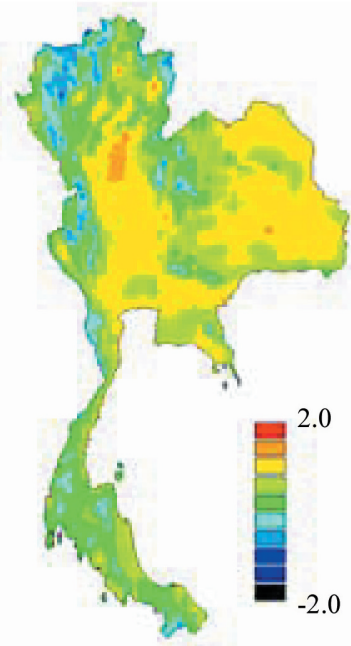

August

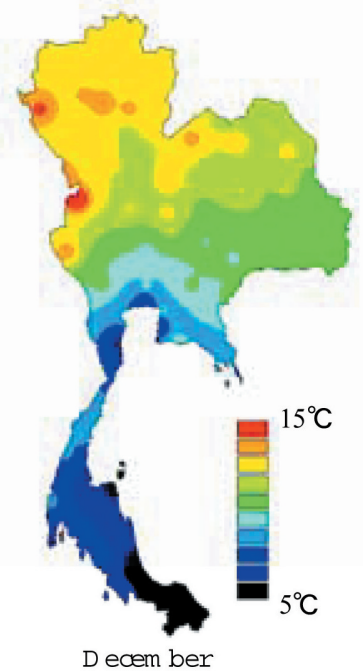

Fig.15. Maps of diurnal range

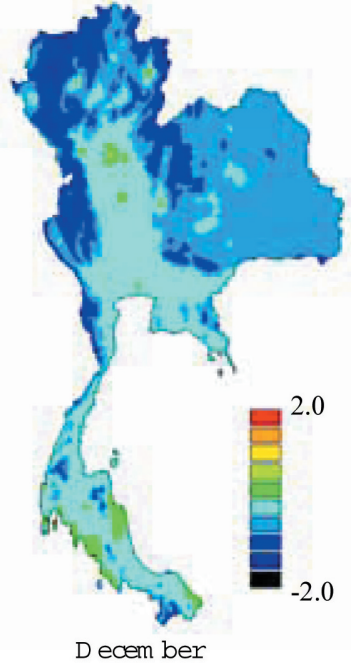

Fig.16. Maps of PMV 